\title{
Disseminated Intravascular Coagulation
}

National Cancer Institute

\section{Source}

National Cancer Institute. Disseminated Intravascular Coagulation. NCI Thesaurus. Code C2992.

A pathological process where the blood starts to coagulate throughout the whole body. This depletes the body of its platelets and coagulation factors, and there is an increased risk of hemorrhage. 